\title{
Machining Precision Research for Two WEDM Processes
}

\author{
Li Xiaojing, Hu Yanhui \\ Mechanical Engineering Department \\ Henan Polytechnic Institute \\ Nanyang, China \\ hnpilxj@126.com
}

\begin{abstract}
Plenty of round holes or especial holes distributed in measuring device and mold component with higher positional requirement, in general, are formed in WEDM technology. In the process of WEDM operation, whole holes with high requirement should be finished in one time, which can avoid of positional error and enhance the positional precision effectively. Investigate into the geometrical tolerance and present in an improved process. This process can both suitable for WEDM-HS and WEDM-LS.
\end{abstract}

Keywords-component; WEDM; Positional precision; Finished accuracy

\section{INTRODUCTION}

Electric discharge machining has gained importance in the manufacturing world since its discovery 50 years ago by B. R. Lazarenko and N. I. Lazarenko[1]. In recent years, research has successfully shown that EDM can be applied to conductive hard and brittle materials if the electrical resistivity is low. One important characteristic of the EDM is very low efficiency of sparking in the forms of frequent open circuit, arcing pulse, and short circuit.

EDM is a machining method primarily used for hard metals or those that would be impossible to machine with traditional techniques. One critical limitation, however, is that EDM only works with materials that are electrically conductive[2]. EDM or Electrical Discharge Machining, is especially well-suited for cutting intricate contours or delicate cavities that would be difficult to produce with a grinder, an end mill or other cutting tools. Metals that can be machined with EDM include hast alloy, hardened toolsteel, titanium, carbide, inconel and kovar[3].

In the process of machining, the system take molybdenum wire as cutting tool electrode, the wire cylinder instruct molybdenum wire move along positive and alternate direction and the pulse power supply processing energy. Pouring liquid medium into the space of wire electrode and workpiece[4]. At the same time, the workbench moves in two coordinate directions of horizontal plane according to control procedures. In according to the spark gap, the two servo consequently drive the platform movement, the various curve guide the workpiece cutting path[5]. The WEDM can be classified as high-speed wire-EDM machine mode and low-speed wire-EDM machine mode. Both the two machine modes are shown in Fig.2 and Fig.3. The main technical items of two working modes are compared in Table.1. The common machining steps and requirements of WEDM is shown in Fig.4.
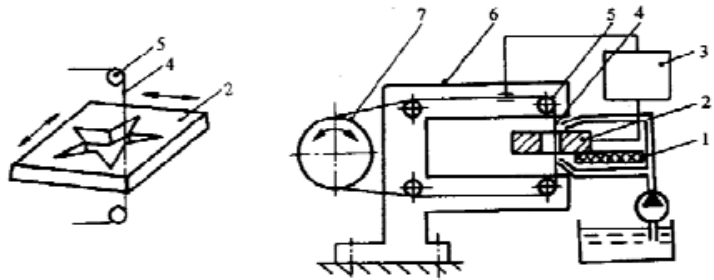

Fig.2 High-speed wire-EDM machine mode

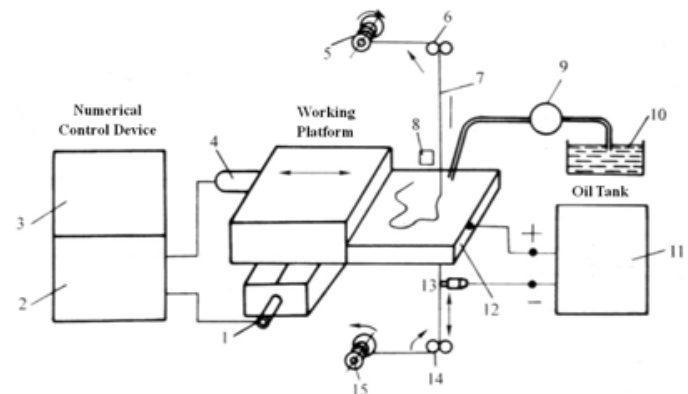

Fig. 3 Low-speed wire-EDM machine mode Table. 1 Comparison of two cutting machine process

\begin{tabular}{|c|c|c|}
\hline $\begin{array}{c}\text { Main technical } \\
\text { items }\end{array}$ & $\begin{array}{c}\text { High-speed } \\
\text { wire-EDM } \\
\text { machine mode }\end{array}$ & $\begin{array}{c}\text { Low-speed wire- } \\
\text { EDM machine } \\
\text { mode }\end{array}$ \\
\hline $\begin{array}{c}\text { Wire feeding } \\
\text { speed (m/mm) }\end{array}$ & $360 \sim 660$ & $1 \sim 15$ \\
\hline $\begin{array}{c}\text { Wire feeding } \\
\text { direction }\end{array}$ & Alternate motion & $\begin{array}{c}\text { Directed } \\
\text { movement }\end{array}$ \\
\hline Wire electrode & $\begin{array}{c}\text { Molybdenum } \\
\text { wire }\end{array}$ & $\begin{array}{c}\text { Copper wire, } \\
\text { tungsten wire }\end{array}$ \\
\hline Operating fluid & $\begin{array}{c}\text { Emulsified } \\
\text { liquid }\end{array}$ & Deionized water \\
\hline $\begin{array}{c}\text { Discharging } \\
\text { gape (mm) }\end{array}$ & 0.01 & $0.02 \sim 0.05$ \\
\hline $\begin{array}{c}\text { Cutting speed } \\
\text { (m }{ }^{2} / \text { mm) }\end{array}$ & $20 \sim 160$ & $20 \sim 240$ \\
\hline $\begin{array}{c}\text { Finished } \\
\text { roughness (Ra) }\end{array}$ & $3.2 \sim 1.0$ & $1.6 \sim 0.2$ \\
\hline $\begin{array}{c}\text { Repeatability } \\
\text { precision (mm) }\end{array}$ & \pm 0.01 & \pm 0.002 \\
\hline $\begin{array}{c}\text { Wire electrode } \\
\text { loss }\end{array}$ & 0.01 & Ignore \\
\hline $\begin{array}{c}\text { Main technical } \\
\text { items }\end{array}$ & $\begin{array}{c}\text { High-speed } \\
\text { wire-EDM } \\
\text { machine mode }\end{array}$ & $\begin{array}{c}\text { Low-speed wire- } \\
\text { EDM machine } \\
\text { mode }\end{array}$ \\
\hline
\end{tabular}




\begin{tabular}{|c|c|c|}
\hline $\begin{array}{c}\text { Wire feeding } \\
\text { speed (m/mm) }\end{array}$ & $360 \sim 660$ & $1 \sim 15$ \\
\hline $\begin{array}{c}\text { Wire feeding } \\
\text { direction }\end{array}$ & Alternate motion & $\begin{array}{c}\text { Directed } \\
\text { movement }\end{array}$ \\
\hline Wire electrode & $\begin{array}{c}\text { Molybdenum } \\
\text { wire }\end{array}$ & $\begin{array}{c}\text { Copper wire, } \\
\text { tungsten wire }\end{array}$ \\
\hline Operating fluid & $\begin{array}{c}\text { Emulsified } \\
\text { liquid }\end{array}$ & Deionized water \\
\hline $\begin{array}{c}\text { Discharging } \\
\text { gape (mm) }\end{array}$ & 0.01 & $0.02 \sim 0.05$ \\
\hline $\begin{array}{c}\text { Cutting speed } \\
\text { (m²/mm) }\end{array}$ & $20 \sim 160$ & $20 \sim 240$ \\
\hline $\begin{array}{c}\text { Finished } \\
\text { roughness (Ra) }\end{array}$ & $3.2 \sim 1.0$ & $1.6 \sim 0.2$ \\
\hline $\begin{array}{c}\text { Repeatability } \\
\text { precision (mm) }\end{array}$ & \pm 0.01 & \pm 0.002 \\
\hline $\begin{array}{c}\text { Wire electrode } \\
\text { loss }\end{array}$ & 0.01 & Ignore \\
\hline
\end{tabular}

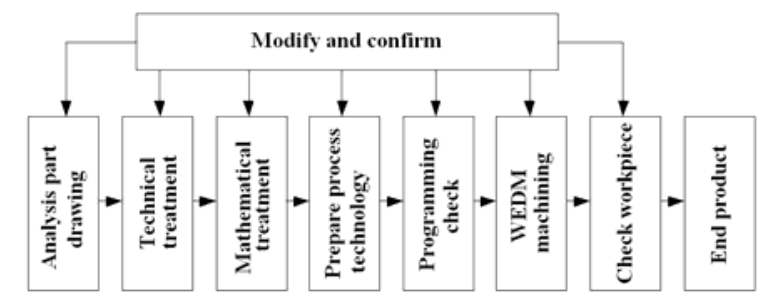

Fig.4 Machining steps and requirements of WEDM

An example is provide to demonstrate, which is shown in Fig.4. The example is a punch concave die with special holes. The material of workpiece is $\mathrm{Cr} 12 \mathrm{MoV}$ steel with the thickness of $30 \mathrm{~mm}$ and hardness of 58 62HRC. In additional, the diameter of guide sleeve mounting holes are $\Phi 20$ and $\Phi 22$, the middle of the irregular hole is concave die shape hole. According to technical regulation, the primary task of machine concave die is to ensure the positional precision of $\Phi 20, \Phi 22$ and irregular holes.

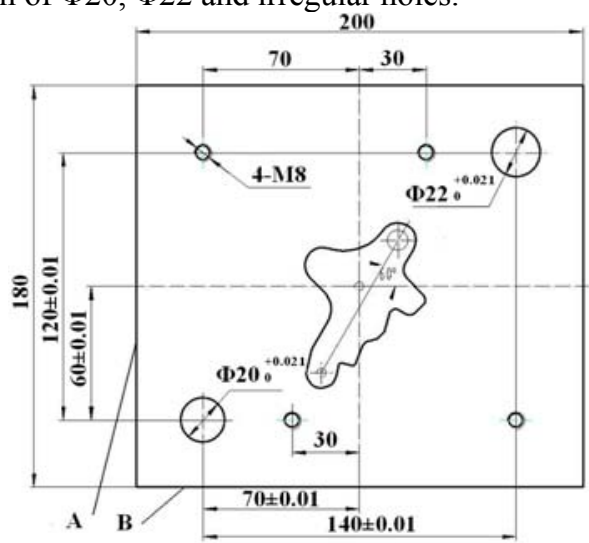

Fig.4 Drawing of Concave die part

\section{GENERAL PROCESS}

During the cutting of shape hole with general process, the hole for molybdenum silk is often employed in order to locate electrode wire, so the form and position accuracy of hole for molybdenum silk must be guaranteed. The hole for molybdenum silks are made by jig grinding finish machining which is beneficial for location of the electrode wire during cutting and ensure position accuracy.

The machine process of the workpiece is below.

01 Preparation dimension. 200X180X35

02 Milling end surface

03 Grinding flat surface with the thickness of 31.5

$04 \mathrm{CNC}$ milling. Milling base surface process and drilling hole from $\Phi 20$ to $\Phi 19.5$, drilling hole from $\Phi 22$ to $\Phi 21.5$. Drilling the irregular hole for molybdenum silk to Ф3.5. Machining four M8 holes with center drill

05 clamping. drilling and tapping

06 Quenching with the requirement temperature

07 Grinding surface with the thickness of 30

08 Jig grinding. Grinding the hole of $\Phi 20$ and $\Phi 22$ to the requirement.

09 Machining the shape hole with WEDM

If the mutually perpendicular surfaces are utilized to locate electrode wire, though the hole for molybdenum silk need not finish machining, the surface $A$ and the surface $B$ in Fig. 1 need finish machining. There is error in positioning electrode wire, furthermore, workpiece must be supported in the form of cantilever, which lowers reliability.

The above process can satisfy present requirement of position accuracy, but the process is complicated. Besides WEDM, finish machining include jig grinding. The process is not economical and efficient. Under machining shape hole through WEDM, when finish hole for molybdenum silk is used as positioning, there is positioning error. It take much time to prepare machining.

\section{THE IMPROVED TECHNOLOGY PROCESS}

The traditional process is improved which can be described as follow.

01 Preparation dimension $200 \times 180 \times 35$

02 Milling end surface

03 Grinding flat surface with the thickness of 31.5

$04 \mathrm{NC}$ milling, milling the datum surface, drilling the hole of $\Phi 20, \Phi 22,4-\mathrm{M} 8$

05 Benching and drilling the thread hole, drilling Ф20,Ф22 and $\Phi 4$ pylome

06 Quenching with the requirement temperature

07 Grinding flat surface with the heights of 30

08 process shape hole with WEDM

From the view of process content, the improved process 04 is less, and just need to drill a few center holes, reducing the boring time. The improved process 08 is to cut out all holes in one time, although the processing time increases, the efficiency is certainly higher than the process of boring and grinding. When aligning, just align a work-piece side (as the front), while the electrode wire locates the hole center only by eyeballing and saves more alignment time. Which completely avoids the alignment error, the location accuracy after processing only relate to the precision of the device.

When cutting the first hole, it doesn't need precise positioning of electrode wire, when cutting the subsequent holes, positioning of the electrode wire is ensured by the machine to that eliminates alignment error of the center hole. 


\section{CUTTING ROUTES AND PROCEDURES}

Such as using HS-WEDM to process the graphic above, the $3 \mathrm{~B}$ procedure generated by CAXA cutting software is as follows.

\begin{tabular}{|c|c|c|c|c|c|}
\hline $\mathrm{N}$ 1. B & $9900 \mathrm{~B}$ & $0 \mathrm{~B}$ & 9900 GX & L1. & -217.326 \\
\hline 8.689 & & & & & \\
\hline$\underset{8.689}{\mathrm{~N}}$ 2. B & $9900 \mathrm{~B}$ & $0 \mathrm{~B}$ & $39600 \mathrm{GY}$ & NR1. & -217.326 \\
\hline$\underset{3.689}{\mathrm{~N}}$ 3. $\mathrm{B}$ & $9900 \mathrm{~B}$ & $0 \mathrm{~B}$ & $9900 \mathrm{GX}$ & L3. & -227.226 \\
\hline $\mathrm{N}$ 4. D & & & & & \\
\hline$\underset{18.689}{\mathrm{~N}} 5 . \mathrm{B}$ & $70000 \mathrm{~B}$ & $60000 \mathrm{~B}$ & $370000 \mathrm{GX}$ & L1 & -157.226 \\
\hline $\mathrm{N}$ 6. D & & & & & \\
\hline$\underset{34.938}{\mathrm{~N}}$ 7. B & $3005 \mathrm{~B}$ & $16249 \mathrm{~B}$ & $16249 \mathrm{GY}$ & L2 & -160.231 \\
\hline N 34. B & $3005 \mathrm{~B}$ & $16248 \mathrm{~B}$ & $316248 \mathrm{GY}$ & L4 & -157.225 \\
\hline $\begin{array}{l}18.689 \\
\mathrm{~N} 35 . \mathrm{D}\end{array}$ & & & & & \\
\hline $\begin{array}{l}\mathrm{N} 36 . \mathrm{B} \\
78.689\end{array}$ & $70000 \mathrm{~B}$ & $60000 \mathrm{~B}$ & B $70000 \mathrm{GX}$ & $\begin{array}{ll}X & \text { L1 }\end{array}$ & -87.225 \\
\hline 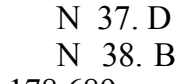 & $10902 \mathrm{~B}$ & $0 \mathrm{~B}$ & 10902 GX & L1 & -76.323 \\
\hline 178.689 & & & & & \\
\hline $\begin{array}{l}\text { N 39. B } \\
78.689\end{array}$ & $10902 \mathrm{~B}$ & $0 \mathrm{~B}$ & $43608 \mathrm{GY}$ & NR1 & -76.323 \\
\hline $\begin{array}{l}\mathrm{N} \\
78.689\end{array}$ & $10902 \mathrm{~B}$ & $0 \mathrm{~B}$ & 10902 GX & L3 & -87.225 \\
\hline
\end{tabular}

$\mathrm{N}$ 41. DD

$\mathrm{N} 1 \sim \mathrm{N} 3$ is the cutting process for $\Phi 20$ hole, $\mathrm{N} 2$ is for cutting round, $\mathrm{N} 1$ and $\mathrm{N} 3$ are feed and return, respectively, which are necessary for each part of the graphics. N4 is the pause, suggesting the operator undo the wire. N5 is the Hopstop procedure, the position of table moves from $\Phi 20$ center to the center of irregularly-shape hole. N6 is the pause. $\mathrm{N} 7 \sim \mathrm{N} 34$ is for the procedure of irregularly-shape holes. $\mathrm{N} 38 \sim \mathrm{N} 40$ is for the processing of $\Phi 22$ hole. N41 is the end. N35 and the N4, N36 and N5, N37 and N6 have the same meaning.

The process measures to solve misalignment of the start and end point

Although inside and outside shape cutting ensures location accuracy, the misalignment appears at the start point and end point of every closed graphics, the produced macroeffect is that, convex hall would appear in there, as shown in Fig.5.

The main reason of producing this kind of situation is that span of wire electrode is bigger when the distance between upper guide wheel and under guide wheel on machine tool is larger. The force generated by electrodischarge when cutting processing will make electrode wire bend and wire electrode deviate a tiny distance. Sketch map about wire electrode force offset is shown in Fig.6. The first section and last section of linear wire electrode will be affected by radial inward force when cutting round hole in
Fig.5 is linear, so right quadrant point in round contour would leave convex bag.

The method to solve the defects is that continue cutting a certain distance along circumference direction after round cutting completion, then returns to starting point of the last part line. Inserting two parts program between N2 and N3 in the above mentioned procedure is available. As shown below.

B 9900 B 0 B 1000 GY NR1; // excess cutting part at counterclockwise more

B 9848 B 1000 B 1000 GY SR1; // return to starting point of $\mathrm{N} 3$

The remaining two contour graphics can adopt to this method, which ensured precision and shape of tolerance of each outline graphic and reduced fitter grinding and polishing workload.

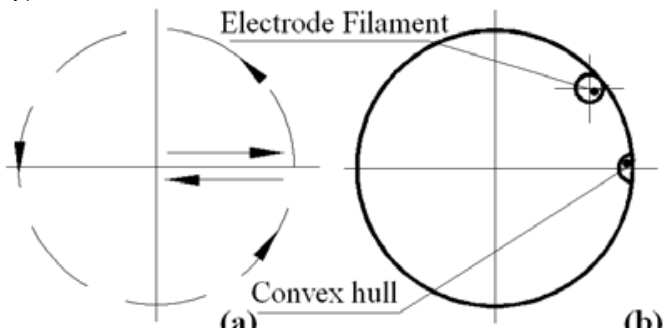

Fig. 5 Convex hull formed by misalignment of the start and end point. a. cutting path. b. the convex hull

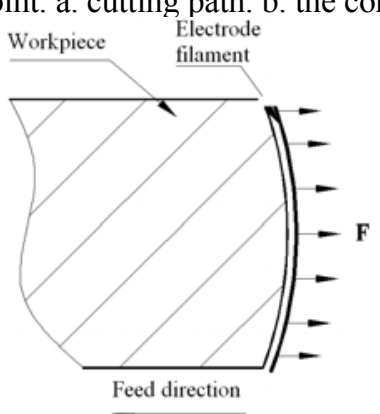

Fig. 6 The offset of the electrode filament

\section{CONCLUSION}

WEDM wire-cutting processing is a special machining method using pulse discharge happens between electrodes and workpieces. This paper have analyzed and compared the two working modes of high-speed wire-EDM machine and low-speed wire-EDM machine. For the holes or slots distributed in mould device should be machined by WEDM method and could meet technical regulation. If all the holes or slots with higher accuracy requirement are machined in one process, the form accuracy and positional accuracy mighty be achieved. The paper compared two machining methods for the special holes with experiment. The result indicates that the improved process can greatly improve the machining accuracy and this method can be used in WEDMHS and WEDM-LS process.

\section{REFERENCES}

[1] Norliana Mohd Abbas, Darius G. SolomonMd. A review on current research trends in electrical discharge machining (EDM). 
International Journal of Machine Tools and Manufacture, Vol 47, Issues 7-8, June 2007, P1214-1228

[2] K. H. Ho, S. T. Newman. State of the art electrical discharge machining (EDM). International Journal of Machine Tools and Manufacture, Vol 43, Issue 13, October 2003, P1287-1300

[3] Mu-Tian Yan, Chen-Wei Huang, Chi-Cheng Fang. Development of a prototype Micro-Wire-EDM machine. Journal of Materials Processing Technology, Vol 149, Issues 1-3, 10 June 2004, P99-105

[4] SeongMin Son, HanSeok Lim, A.S. Kumar. Influences of pulsed power condition on the machining properties in micro EDM. Journal of Materials Processing Technology, Volume 190, Issues 1-3, 23 July 2007, P73-76

[5] Xin-long Kang. Relationship between Electrical Parameters in Combined EDM and Surface Quality. Applied Mechanics and Materials Vol. 42, P436-439 